\title{
CONSUMER CHOICE OF DWELLING, NEIGHBORHOOD AND PUBLIC SERVICES*
}

\author{
John M. QUIGLEY \\ University of California, Berkeley, CA 94720, USA
}

Reccived May 1984, final version received August 1984

\begin{abstract}
Previous microeconomic analyses of consumer choice in the housing market have either assumed the independence of irrelevant alternatives or have represented housing heterogeneity by some arbitrary aggregation of dwellings. This paper presents an empirical analysis of housing choice based upon individual households and dwellings which also estimates the degree of independence of neighborhood and dwelling characteristics. The empirical results suggest that the independence assumption may be inappropriate and also that housing choice may be more sensitive to variations in workplace accessibility than is indicated by the more restricted model of household choice.
\end{abstract}

\section{Introduction}

Market demand curves for all commodities arise from the discrete consumption decisions of individual households, and for many commodities, especially durable goods, it is more natural to frame the individual consumption decision as a binary choice - to buy or not to buy - in a given period. In a market like the one for housing, where all consumers are observed to choose some dwelling and where alternatives are extremely heterogeneous, the individual consumption decision is the choice of one unit out of a large set of discrete alternatives. In making these choices, housing consumers presumably sample from a large number of available dwellings. They evaluate the physical characteristics of these dwellings, the neighborhoods in which they are located, and the public services provided to them. On the basis of these evaluations and the prices at which dwellings are offered, the consumer ultimately chooses one dwelling out of the sampled alternatives.

Consumer choice in the housing market thus has three distinguishing features: first, in almost all cases, the consumer selects one and only one good out of a large population of alternatives; second, the bundle of services provided by any dwelling is extremely heterogeneous; third, consumer choice

*This project was initially supported by a grant on the measurement of economic and social performance from the National Science Foundation (SES-772368); additional resources were provided by the Federal Home Loan Bank of San Francisco and the Center for Real Estate and Urban Economics, University of California, Berkeley. This research benefited from support of Joseph Humphrey, Michael Jessee, and Richard Ruggles and from the research assistance of Paul Pfleiderer and Carl Mason. 
involves the selection of a price as well as the other characteristics associated with dwellings.

This paper considers the problem of consumer choice in the housing market from this broader perspective. Section 2 reviews briefly the basic model of discrete choice, and notes previous empirical analyses applying this model to the housing market. Section 3 presents an empirical analysis of a somewhat more general treatment of household choice in the market for residential housing. The empirical analysis is a direct generalization of Quigley (1983) and analyzes consumer choice of dwelling unit, neighborhood, and public sector attributes.

\section{The generalized multinominal choice model}

When a consumer chooses a dwelling unit $i$ out of the set of all dwellings $D$, he selects a set of housing characteristics, neighborhood and public service amenities and a journey to work $\left(X_{i}\right)$, as well as price (that is, a monthly rent or purchase price, $R_{i}$ ). Consumers of income $y$ have preferences over the set of public service-amenity packages, housing characteristics, and other goods, $y-R_{i}$.

Assume the utility function for households consists of a systematic component $V$ and an additive stochastic component $\varepsilon$ :

$$
U\left[X_{i}, y-R_{i}\right]=V(i)+\varepsilon .
$$

Assumptions about the form of the stochastic component of the utility function permit probability statements about the choice of any spccific dwelling to be made. In particular, as is well known, McFadden (1974) demonstrated that: if it is assumed that the stochastic terms are independently and identically distributed according to the Wcibull distribution, then the form of the probability statement is

$$
p(i)=\operatorname{prob}[U(i)>U(j)]=\frac{\mathrm{e}^{V(i)}}{\sum_{j} \mathrm{e}^{V(j)}}, \text { for all } j .
$$

Eq. 2 is a well-behaved probability statement with values bounded by zero and one. The probability of choosing any dwelling unit depends upon the characteristics of all dwellings in the choice set. Eq. (2) is estimated by maximizing a log-likelihood function $L$ of the form

$$
\log L \propto \frac{1}{k} \sum_{k} \log \frac{\mathrm{e}^{V(i)}}{\sum_{j} \mathrm{e}^{V(j)}}
$$

for a sample size of $k$ observations on choices $i$ and on available alternatives $j$. 
Finally, if the systematic component of the utility function is linear in its parameters, McFadden has shown that the likelihood function given in eq. (3) is concave, and the parameters are unique up to a factor of proportionality. For the problem of housing choice, a linear relationship,

$$
V(i)=\alpha_{i} X_{i}+\beta\left(y-R_{i}\right)
$$

renders the parameters $\alpha_{i}$ and $\beta$ of the model estimablc.

Under the maintained hypotheses of eqs. (1), (2), and (4), estimates of the discrete model of housing choice have been presented by a number of researchcrs [Casc (1981), Ellickson (1977,1981), Kain and Apgar (1977), Lerman (1977, 1979), Quigley (1976), Williams (1979)]. All of these empirical analyses share at least two limitations.

First, according to eq. (2), the odds of choosing housing unit $m$ relative to $n$ are independent of the characteristics of all other alternatives available to consumers. This maintained hypothesis, the so-called independence of irrelevant alternatives (IIA), is simply not testable within the traditional model. The assumption is surely inappropriate in many situations involving the choice of housing and neighborhood characteristics.

Second, there is a real practical problem in maximizing the log-likelihood function in eq. (3). Clearly, the theoretical problem solved by consumers in the marketplace is the selection of one specific dwelling unit out of the large number of alternative dwellings $(D)$ actually available on the market. However, for an economist to maximize the likelihood function in eq. (3) for any sample of consumers, it is necessary to make the set of alternatives 'small enough' somehow ${ }^{1}$ to render an iterative solution computationally feasible. ${ }^{2}$

The bundle of services associated with a dwelling unit can be partitioned into several components: for example, those that vary by dwellings within neighborhoods or census tracts or towns, $X_{1}$, (e.g., size or condition) and those that are constant for dwellings within neighborhoods but vary across neighborhoods $X_{2}$ (e.g., the quality of local schools).

\footnotetext{
${ }^{1}$ This latter complication did not arise at all in the original applications of the multinominal logistic model to the choice of transport modes. Inherently, there are a relatively small number of available transport modes. In contrast, however, there are a large number of potential dwelling units available for occupancy by housing consumers.

${ }^{2}$ Typically, analysts of the housing market have 'solved' this latter problem in an ad hoc way. They have represented the heterogeneity of the housing, neighborhood, and public services available to consumers by a small number of 'types' of residential housing (i.e., specified components of the bundle of housing services at particular values). Thus, in practical estimation, the choice problem has been defined as the selection of one housing type out of an arbitrarily defined set of housing types (i.e., Case analyzed consumer choice among 9 types of units defined by tenure, size and structure classes; Lerman analyzed consumer choice among 145 census tracts).
} 
The probability of choosing neighborhood $(n)$ and dwelling unit $(i)$ is $^{3}$

$$
p(i, n)=\frac{\mathrm{e}^{\alpha_{1} X_{1 i}+\alpha_{2} X_{2 n}}}{\sum_{j, k} \mathrm{e}^{\alpha_{1} X_{1 j}+\alpha_{2} X_{2 k}}} .
$$

This joint probability can be decomposed into a marginal and a conditional probability. Let $\sigma$ be an unknown parameter; if $\sigma=0$, then

$$
\begin{aligned}
p(i \mid n) & =\frac{\mathrm{e}^{\alpha_{1} X_{1 i} /(1-\sigma)}}{\mathrm{e}^{I_{n}}}, \\
p(n) & =\frac{\mathrm{e}^{\alpha_{2} X_{2 n}+(1-\sigma) I_{n}}}{\sum \mathrm{e}^{\alpha_{2} X_{2 k}+(1-\sigma) I_{k}}}, \\
I_{n} & =\log \sum \frac{\mathrm{e}^{\alpha_{1} X_{1 i}}}{1-\sigma}
\end{aligned}
$$

is arithmetically identical to eq. (5). The parameters of the choice model can be estimated directly by using eq. (5) or sequentially by estimating $\alpha_{1}$ from eq. (6a), using the parameters to calculate $I_{n}$ for each neighborhood (or census tract or town) and then estimating $\alpha_{2}$ from eq. (6b). The sequential approach 'involves some loss of efficiency relative to direct estimation of the joint choice model' [McFadden (1978)]; it is, however, merely an alternative way of approaching the same problem.

Sequential estimation of eq. (6) also provides a test of whether $\sigma$ is different from zero. Domencich and McFadden (1975) have shown that the joint probability function consistent with eq. (6) is of the form

$$
p(i, n)=\frac{\mathrm{e}^{V(i, n) /(1-\sigma)}\left[\sum \mathrm{e}^{V(j, n) /(1-\sigma)}\right]^{-\sigma}}{\left[\sum \sum \mathrm{e}^{V(j, k) /(1-\sigma)}\right]^{(1-\sigma)}} .
$$

This is a direct generalization of the choice problem. If $\sigma$ is indeed equal to zero, then eq. (7) reduces to eq. (2), that is, to a choice model with the IIA property. If $\sigma$ is equal to one, then from eq. (6b) the choice of neighborhood depends only upon neighborhood attributes; that is, all housing units within a neighborhood are viewed as identical. Thus sequential estimation of eq. (6) provides a direct statistical test of the degree of independence of irrelevant alternatives.

\footnotetext{
${ }^{3}$ For exposition only, the notation describes the choice made by a household of given income, so that $\left(y-R_{i}\right)$ can be treated as one component of the vector $X_{1 i}$ that varies across dwellings. Since income $y$ is invariant among choices, in this linear form choice probabilities are unaffected by level of income.
} 
Now consider the problem of estimating the theoretically correct choice modcl - the selection of one dwelling unit out of a large number of discrete alternatives. To estimate the choice model using as observations the entire set of metropolitan housing alternatives facing each consumer is clearly out of the question. If, however, for each consumer we select a subset of alternatives, $d$, and observe the consumer's choice among elements in this subset, then it is possible to obtain consistent estimates of the theoretically correct choicc modcl. In particular, suppose $f(d \mid i)$ is the sampling rule for obtaining subset $d$, conditional upon the observed choice of dwelling unit $i$. McFadden (1978) has shown that if the sampling rule satisfies certain properties, that is,

$$
\text { if } f(d \mid i)>0 \text { then } f(d \mid j)>0,
$$

then maximization of the modified likelihood function,

$$
\log L \propto \frac{1}{K} \sum_{K} \log \frac{\mathrm{e}^{V(i)+\log f(d \mid i)}}{\sum_{(j \text { in } d)} \mathrm{e}^{V(j)+\log f(d \mid j)}},
$$

yields consistent estimates of the parameters of the choice function. Eq. (8) specifies a sampling rule with the property that if rejected alternative $j$ is assigned to the subset $d$, then it is logically possible that $j$ could have been the observed choice. Under these conditions, Mctadden's result indicates that the likelihood function need only be modified to take into account the sampling rule for selecting $d$. Thus it is possible to estimate, consistently at least, the parameters of the model that views households as choosing one specific dwelling unit of the entire set of available units in the metropolitan housing market.

Two papers have applied these results in a partial manner in the analysis of the housing market: First, Lerman's analysis (1977) of household choice of census tract includes a variable representing the logarithm of the number of dwellings in each tract. Lerman interprets the coefficient of this variable as providing a direct test of the IIA assumption, that is, as a measurement of the degree of substitution among dwelling units, given census tracts. This is because eq. (6c) can be written as

$$
\begin{aligned}
I_{n} & =\log \sum \mathrm{e}^{\alpha_{1} X_{1 i} /(1-\sigma)} \\
& =\frac{\bar{X}_{1}}{(1-\sigma)}+\log N_{n}+\log \frac{1}{N_{n}} \sum \frac{\mathrm{e}^{\left(\alpha_{1} X_{1 i}-\bar{X}_{1}\right)^{2}}}{1-\sigma}
\end{aligned}
$$

where

$$
\bar{X}_{1}=\frac{1}{N_{n}} \sum_{N_{n}} \alpha_{1} X_{1 i}
$$


and $N_{n}$ is the number of dwellings in neighborhood $n$. If all dwellings within a neighborhood are identical, the last term in the above equation is zero and the coefficient on $\log N_{n}$ is $(1-\sigma)$, the degree of independence of irrelevant alternatives within a census tract.

Second, Quigley's recent analysis (1983) of housing choice is based upon a research design which samples dwellings according to eq. (8), thereby providing consistent estimates of the choice of individual dwellings. However, the sampling structure adopted did not permit any analysis of the degree of substitution of neighborhoods or towns. ${ }^{4}$

\section{Empirical analysis}

In this section, we consider the household choice of dwelling. This choice involves consideration of the physical characteristics of structures and parcels, the selection of a neighborhood, the social and economic characteristics of neighbors and the accessibility of that neighborhood to the planned economic activities of the household. The selection of a particular dwelling is also inextricably linked to the choice of a city or town - and to the collection of public services and taxes provided by that political jurisdiction.

The empirical results discussed below are based upon analysis of a home interview sample conducted in 1967 in the Pittsburgh metropolitan housing market by the Southwestern Pennsylvania Regional Planning Commission (SPRPC). The basic data file consists of information on 24,626 households and the dwellings they occupied. From this sample of households, we randomly selected a subsample of renter households who had moved into their present dwellings within the past year and for whom complete data were available. The subsample consists of observations on the housing choices of 584 recent mover rental households in the Pittsburgh metropolitan area. Table 1 presents a summary of the characteristics of these households, generally lower middle income renters with small families. The modal family size is two and the average is about three persons per household. About seventy percent of the households had one worker, but the average was 1.3 workers per household. More than ninety percent of household heads were employed full time. Five sixths of the households were classified as white, and more than eighty percent included an adult male. The average household income was $\$ 7,300$ in 1967 dollars (or about $\$ 18,700$ in 1980 dollars).

\footnotetext{
${ }^{4}$ The sampling rule employed generated only a small sample of rejected alternatives for each household and did not ensure any geographical clustering of observations. Hence, it was only possible to consider the degree of substitution of central city and non-central city dwellings. The analysis reported in this paper overcomes this limitation by sampling dwellings, neighborhoods and towns in a systematic way. See section 3.2.
} 
Table 1

Characteristics of 584 sample households."

\begin{tabular}{|c|c|c|c|c|}
\hline & Mean & $\begin{array}{l}\text { Standard } \\
\text { deviation }\end{array}$ & Minimum & Maximum \\
\hline \multicolumn{5}{|l|}{ A. Summary Characteristics } \\
\hline Family size & 2.921 & 1.603 & 1 & 13 \\
\hline Number of workers & 1.339 & 0.578 & 1 & 5 \\
\hline $\begin{array}{l}\text { Household income } \\
\text { (thousands of } 1967 \text { dollars) }\end{array}$ & 7.313 & 3.993 & 2.5 & 35.0 \\
\hline \multicolumn{5}{|l|}{ B. Frequency distributions } \\
\hline $\begin{array}{l}\text { Family size } \\
\text { One } \\
\text { Two } \\
\text { Three } \\
\text { Four } \\
\text { Five or more }\end{array}$ & & $\begin{array}{l}\text { Percent } \\
16.1 \\
30.0 \\
26.4 \\
14.2 \\
13.3\end{array}$ & & \\
\hline $\begin{array}{l}\text { Number of workers } \\
\text { One } \\
\text { Two } \\
\text { Three } \\
\text { Four or more }\end{array}$ & & $\begin{array}{r}70.5 \\
25.9 \\
2.9 \\
0.7\end{array}$ & & \\
\hline $\begin{array}{l}\text { Head's employment } \\
\text { Full time } \\
\text { Part time } \\
\text { Student } \\
\text { Unemployed }\end{array}$ & & $\begin{array}{r}90.0 \\
3.6 \\
4.6 \\
0.9\end{array}$ & & - \\
\hline $\begin{array}{l}\text { Race } \\
\text { White } \\
\text { Non-white }\end{array}$ & & $\begin{array}{l}83.2 \\
16.8\end{array}$ & & \\
\hline $\begin{array}{l}\text { Composition } \\
\text { Adult male present } \\
\text { No adult male present }\end{array}$ & & $\begin{array}{l}80.8 \\
19.2\end{array}$ & & \\
\hline
\end{tabular}

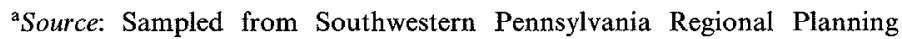
Commission home interview conducted in 1967.

\subsection{The nested choice model}

We consider household choice in three stages: the choice of dwelling, given neighborhood and town $P(i \mid n, t)$; the choice of ncighborhood, given town $P(n \mid t)$; and the marginal choice of the services and amenities provided by any town, $P(t)$. Fig. 1 illustrates the structure of the nested logit analysis and indicates the rule used to generate the sample of alternatives. From fig. 1 suppose that we observe that some household has chosen dwelling $i_{1}$, in neighborhood $n_{1}$, and town $t_{1}$. Suppose further that we observe 19 rejected 


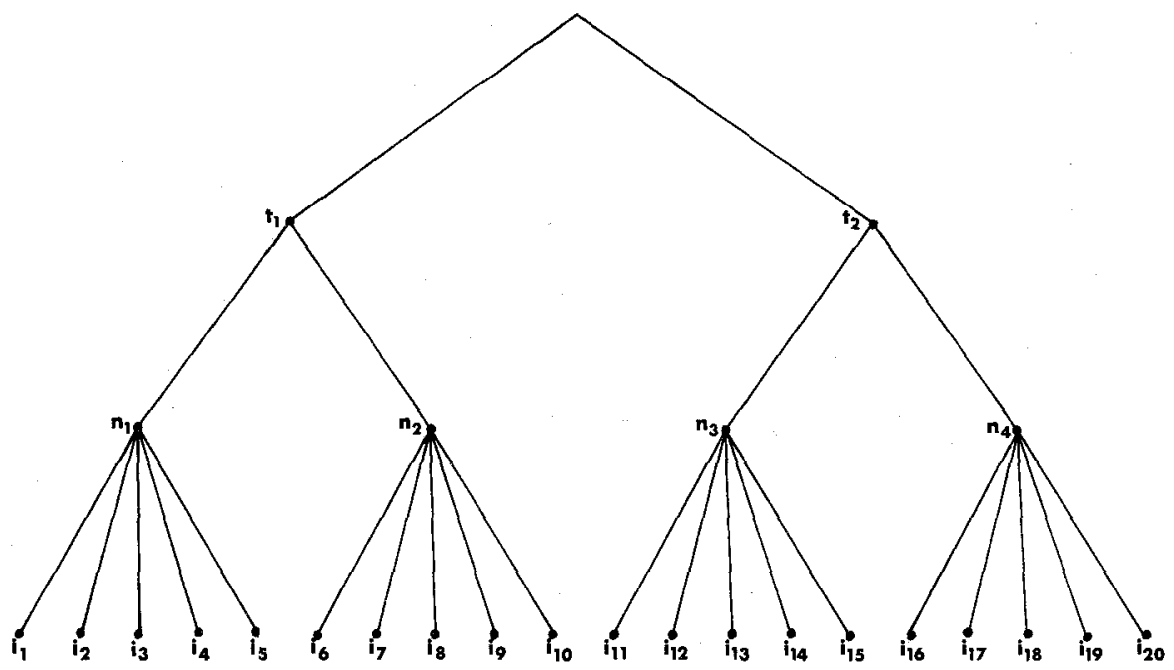

Fig. 1. Nested structure of dwelling, neighborhood and public sector choice.

dwellings, including 4 in the chosen town. Observations on chosen dwellings $i_{1}$, and rejected dwellings $i_{2}$ through $i_{5}$ for sample of households permit the parameters of the conditional probability function $p(i \mid n, t)$ of the form of (6a) to be estimated. These parameters, in turn permit an estimate of the inclusive value $I_{n}$ to be computed for each of the four neighborhoods.

For example, the coefficients $\alpha_{i}$ of the dwelling characteristics permit estimates of the mean value $\bar{X}_{n}$ for a dwelling within a neighborhood and its variance $W_{n}$ to be computed,

$$
\begin{aligned}
& \bar{X}_{n}=(1 / 5) \sum \alpha_{i} X_{1 i}, \\
& W_{n}=(1 / 4) \sum\left(\alpha_{i} X_{1 i}-\bar{X}_{n}\right)^{2},
\end{aligned}
$$

and thus, the inclusive value for neighborhoods can be estimated as

$$
I_{n}=\frac{1}{(1-\sigma)} \vec{X}_{n}+1 \log N_{n}+\frac{1}{2(1-\sigma)^{2}} W_{n}
$$

where $N_{n}$ is the number of dwellings in neighborhood $n$.

Given this information, observations on chosen neighborhood $n_{1}$ and rejected neighborhood $n_{2}$ permit the parameters of the conditional probability function $P(n \mid t)$ of the form of $(6 \mathrm{~b})$ to be estimated, as well as the coefficient on the inclusive value $I_{n}$. Finally, these parameters allow an estimate of the inclusive value $I_{t}$ to be computed for each of the two towns; this permits an estimate of the marginal probability function $p(t)$ of the form 
of (6b) to be obtained. Together, these coefficients permit estimation of the joint probability function $p(i, n, t)$, of the form of (7). Besides the stochastic utility parameters associated with dwelling unit, neighborhood, and public service characteristics, this sequential approach yields estimates of coefficients of two inclusive valucs: the inclusive value for neighborhoods given town, indicating the degree to which dwellings are perceived to be similar within neighborhoods, and the inclusive value for towns, indicating the degree to which neighborhoods within towns are perceived to be similar. If these coefficients are each equal to one, it follows that the independence of irrelevant alternatives' assumption is consistent with household behavior.

\subsection{The sampling rule}

Sequential estimation of the choice model considers, in the first stagc, observations on the chosen dwelling and on rejected dwellings in the chosen neighborhood. In the second stage, it considers observations on the chosen neighborhood and one rejected neighborhood in the same town. In the third stage, it considers observations on the chosen town and on one or more rejected towns.

Consider the following sampling rule for obtaining subset $d$. Choose $d$ by including the chosen alternative and by selecting at random $\omega$ rejected alternatives in the same neighborhood. Then the sampling rule is merely

$$
f(d \mid i)=\frac{\omega}{N_{n}-1} .
$$

This sampling rule is clearly consistent with eq. (8), i.e., if any alternative appears in the subset $d$ it has the logical possibility of being the observed choice from that subset. Sampling rule (14) implies a much stronger property however; each alternative appearing in subset $d$ has equal probability of being the observed choice. For this special sampling rule, with the so-called 'uniform conditioning property' [McFadden (1978)], the terms containing $\log f(d)$ in eq. (9) simply cancel. Maximization of the likelihood function based on a sample of observations on choice $i$ out of subsets $d$ yields consistent estimates of the parameters obtained by maximizing the likelihood function based on observations on choices $i$ out of the set of all possible alternatives $D$.

Table 2 summarizes the application of this rule, eq. (14), to the sample of 584 Pittsburgh renter households. Column (1) reports the average characteristics of the dwellings chosen by each of these households. About 20 percent chose single detached rental units and about 32 percent chose units in duplex structures. On average, dwellings were 47 years old, contained 1.9 bedrooms and 1.1 bathrooms. On an ordinal scale of 1 (sound), 2 (deteriorated), 3 
Table 2

Average characteristics of sampled dwellings, neighborhoods and towns (standard deviations in parentheses).

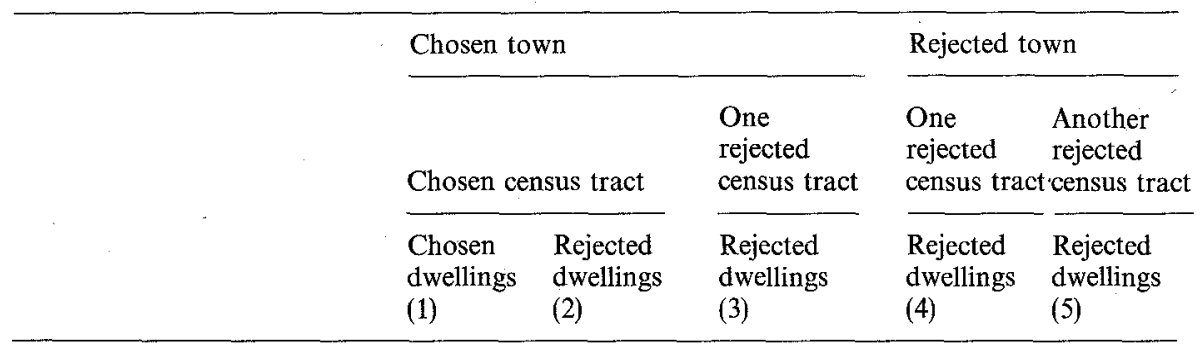

Dwelling characteristics ${ }^{\mathrm{a}}$

Structure type

Single detached $(\%)$

Duplex $(\%)$

Apartment (\%)

Age of structure (years)

Condition

( $1=$ sound; 3 = dilapidated $)$

Bedrooms

Baths

Monthly rent (1967 dollars)

Census tract characteristics ${ }^{\mathbf{b}}$

Auto time to work

(minutes) $^{\mathrm{a}}$

Transit time to work

(minutes) $^{\mathrm{a}}$

Percent non-white

Percent owner occupied

Percent available vacant

Median monthly rent

(1969 dollars)

Percent husband-wife families

$\begin{array}{rrrrr}20.034 & 18.793 & 20.274 & 33.082 & 33.425 \\ 31.507 & 30.479 & 36.952 & 28.733 & 28.767 \\ 46.575 & 49.315 & 41.027 & 37.740 & 37.534 \\ 47.356 & 45.140 & 49.429 & 40.078 & 39.761 \\ (12.11) & (11.98) & (13.14) & (13.91) & (11.68) \\ 1.269 & 1.296 & 1.320 & 1.255 & 1.246 \\ (0.52) & (0.55) & (0.58) & (0.52) & (0.51) \\ 1.888 & 1.845 & 1.909 & 2.072 & 2.066 \\ (0.93) & (0.96) & (0.96) & (0.96) & (0.88) \\ 1.068 & 1.045 & 1.034 & 1.086 & 1.079 \\ (0.40) & (0.36) & (0.35) & (0.36) & (0.36) \\ 80.190 & 75.785 & 67.835 & 70.670 & 69.977 \\ (44.12) & (43.14) & (40.50) & (38.93) & (36.84)\end{array}$

$\begin{array}{rrrrr}25.060 & 25.060 & 29.116 & 44.491 & 44.372 \\ (9.40) & (9.40) & (9.33) & (17.62) & (17.81) \\ 38.464 & 38.464 & 47.327 & 73.253 & 72.625 \\ (25.63) & (25.63) & (23.59) & (42.73) & (42.79) \\ 17.410 & 17.410 & 20.648 & 2.049 & 2.800 \\ (29.19) & (29.19) & (33.17) & (7.51) & (8.10) \\ 41.272 & 41.272 & 44.503 & 66.350 & 65.408 \\ (24.35) & (24.35) & (24.66) & (17.466) & (18.28) \\ 7.624 & 7.624 & 7.621 & 3.908 & 4.406 \\ (11.67) & (11.67) & (11.15) & (8.52) & (10.92) \\ 110.647 & 110.647 & 110.605 & 117.802 & 118.522 \\ (41.85) & (41.85) & (45.40) & (55.41) & (54.55) \\ 51.454 & 51.454 & 52.448 & 69.580 & 68.937 \\ (17.63) & (17.63) & (17.07) & (12.81) & (13.93)\end{array}$


Table 2 (continued)

\begin{tabular}{|c|c|c|c|c|c|}
\hline & \multicolumn{3}{|c|}{ Chosen town } & \multicolumn{2}{|c|}{ Rejected town } \\
\hline & \multicolumn{2}{|c|}{ Chosen census tract } & \multirow{2}{*}{$\begin{array}{l}\begin{array}{l}\text { One } \\
\text { rejected } \\
\text { census tract }\end{array} \\
\begin{array}{l}\text { Rejected } \\
\text { dwellings } \\
(3)\end{array}\end{array}$} & \multirow{2}{*}{$\begin{array}{l}\begin{array}{l}\text { One } \\
\text { rejected } \\
\text { census tract }\end{array} \\
\text { Rejected } \\
\text { dwellings } \\
(4)\end{array}$} & \multirow{2}{*}{$\begin{array}{l}\begin{array}{l}\text { Another } \\
\text { rejected } \\
\text { census tract }\end{array} \\
\begin{array}{l}\text { Rejected } \\
\text { dwellings } \\
(5)\end{array}\end{array}$} \\
\hline & $\begin{array}{l}\text { Chosen } \\
\text { dwellings } \\
\text { (1) }\end{array}$ & $\begin{array}{l}\text { Rejected } \\
\text { dwellings } \\
\text { (2) }\end{array}$ & & & \\
\hline \multicolumn{6}{|l|}{ Town characteristics ${ }^{\mathfrak{c}}$} \\
\hline $\begin{array}{l}\text { School expenditures per } \\
\text { ADM (\$) }\end{array}$ & $\begin{array}{l}761.687 \\
(89.67)\end{array}$ & $\begin{array}{l}761.687 \\
(89.67)\end{array}$ & $\begin{array}{l}761.687 \\
(89.67)\end{array}$ & $\begin{array}{r}963.955 \\
(501.58)\end{array}$ & $\begin{array}{r}956.722 \\
(499.79)\end{array}$ \\
\hline $\begin{array}{l}\text { Percent non-white } \\
\text { (local public school) }\end{array}$ & $\begin{array}{l}35.384 \\
(9.54)\end{array}$ & $\begin{array}{l}35.384 \\
(9.54)\end{array}$ & $\begin{array}{l}35.384 \\
(9.54)\end{array}$ & $\begin{array}{r}9.520 \\
(15.49)\end{array}$ & $\begin{array}{r}9.631 \\
(15.46)\end{array}$ \\
\hline $\begin{array}{l}\text { Local public expenditures per } \\
\text { household (thousands) }\end{array}$ & $\begin{array}{r}3.567 \\
(0.07)\end{array}$ & $\begin{array}{r}3.567 \\
(0.07)\end{array}$ & $\begin{array}{c}3.567 \\
(0.07)\end{array}$ & $\begin{array}{r}4.425 \\
(1.44)\end{array}$ & $\begin{array}{r}4.414 \\
(1.44)\end{array}$ \\
\hline Number of observations & 584 & 2,336 & 2,920 & 2,920 & 2,920 \\
\hline
\end{tabular}

${ }^{2}$ From SPRPC home interview survey and zone to zone travel time matrices. See Quigley (1972) for details.

${ }^{\text {b}}$ From 1970 Census of Housing.

${ }^{\circ}$ Computed from 1970 Census of Governments data using methodology reported in Quigley, Trask, and Trask (1977).

(dilapidated), the average dwelling was 1.3 ; monthly rent averaged $\$ 80$ in 1967 dollars.

On average, these renter households chose neighborhoods (census tracts) that were 25 minutes from their work places by car and about 38 minutes by public transit. They choose neighborhoods that were 83 percent white, where home ownership rates were 41 percent and where the vacancy rate for rental housing was about 8 percent. The median monthly rent reported in the chosen neighborhoods (census tracts) was $\$ 111$ in 1969 dollars. These households chose political jurisdictions where school expenditures were $\$ 762$ per pupil, where the non-white students comprised 35 percent of the public school student body and where local government expenditures were $\$ 3,500$ per household.

Column (2) reports the average characteristics of four rejected dwellings sampled (i.e., $\omega=4$ ) for each household. Each of these dwellings is located in the same political jurisdiction and neighborhood. The dwelling units not chosen by these households tend to be more dense structure types and slightly newer. They also average about $\$ 5$ a month lower in rent than dwellings chosen by these households. Together, the dwelling units described in columns (1) and (2) correspond to units $i_{2}$ through $i_{5}$ in fig. 1. 
The third column of table 2 presents the average characteristics of dwellings $i_{6}$ through $i_{10}$. The dwellings were selected by choosing one rejected census tract within the chosen town $(\omega=1)$ according to sampling rule (14) and then choosing five dwelling units at random $(\omega=5)$. Column (4) presents the average characteristics of dwellings $i_{11}$ through $i_{15}$, again by choosing at random one rejected town, one census tract, and five dwellings; the last column presents the average characteristics of dwellings $i_{16}$ through $i_{20}$ obtained by choosing another census tract in the rejected town, and five dwelling units within that tract.

Altogether we observe the specific dwelling chosen by each household and a sample of 19 rejected dwellings nested in four neighborhoods and two towns.

\subsection{Results}

Table 3 presents estimates of the parameters of the conditional choice of dwelling in several variants. The model includes two measures of residential density (dummy variables representing single detached dwellings and units in duplexes), two measures of the quality of dwellings (an index of structural condition, and the age of structure), two size measures (the number of bathrooms and the number of bedrooms per person), and the amount of money left over for consumption of 'other goods', i.e., monthly income minus rental payments.

Model 1 reports the coefficients of each of these variables in the model predicting dwelling choice, conditional upon the choice of neighborhood and political jurisdiction. The results suggest that these households prefer less dense housing (i.e., single detached dwellings are preferred to duplexes; both are preferred to apartment dwellings, the left out category). The coefficients on the size variables are highly significant, suggesting that households would prefer more space and additional baths. The coefficient on the 'other goods' term indicates that, ceteris paribus, households would prefer more income and lower housing prices.

Model 2 reports the coefficients of a similar model expressed in logarithmic form. As compared to the simple linear model, the coefficients on the logarithmic form are smaller and, in all cases, insignificantly different from zero. The likelihood ratio statistic is clearly insignificant in this formulation.

Model 3 reports the results of a more complex specification - the model includes the same basic measures, but it includes the logarithms of the measures and the interaction of the log of income with each other variable and its square. In this specification, it is more difficult to interpret the sensitivity of household choice to dwelling characteristics. The results present some evidence on the importance of dwelling condition, age, size, and rent on the probability of choice. In general, the results suggest that consumers prefer 
Table 3

Coefficient estimates for dwelling unit choice, given neighborhood and town ( $t$-ratios in parentheses).

\begin{tabular}{|c|c|c|c|}
\hline Variable & $\begin{array}{l}\text { Model } 1 \\
\text { (1) }\end{array}$ & $\begin{array}{l}\text { Model } 2 \\
\text { (2) }\end{array}$ & $\begin{array}{l}\text { Model } 3 \\
\text { (3) }\end{array}$ \\
\hline \multicolumn{4}{|l|}{ Structure type } \\
\hline Single detached & $\begin{array}{r}0.371 \\
(2.53)\end{array}$ & $\begin{array}{c}0.106 \\
(0.73)\end{array}$ & $\begin{array}{c}-0.723 \\
(1.36)\end{array}$ \\
\hline Duplex & $\begin{array}{l}0.256 \\
(2.05)\end{array}$ & $\begin{array}{l}0.096 \\
(0.77)\end{array}$ & $\begin{array}{c}-0.62 \\
(1.45)\end{array}$ \\
\hline Age of structure & $\begin{array}{r}-0.004 \\
(1.50)\end{array}$ & $\begin{array}{c}-0.019^{a} \\
(0.29)\end{array}$ & $\begin{array}{c}-0.791^{\mathrm{a}} \\
(1.51)\end{array}$ \\
\hline Condition & $\begin{array}{c}0.066 \\
(0.64)\end{array}$ & $\begin{array}{c}-0.174^{a} \\
(1.08)\end{array}$ & $\begin{array}{l}1.974^{\mathrm{a}} \\
(2.73)\end{array}$ \\
\hline Baths & $\begin{array}{r}0.299 \\
(2.10)\end{array}$ & $\begin{array}{l}0.262^{\mathrm{a}} \\
(0.84)\end{array}$ & $\begin{array}{l}0.339^{\mathrm{a}} \\
(0.43)\end{array}$ \\
\hline Bedrooms/person & $\begin{array}{r}0.738 \\
(5.68)\end{array}$ & $\begin{array}{l}0.101^{\mathrm{a}} \\
(0.59)\end{array}$ & $\begin{array}{c}-0.625^{\mathrm{a}} \\
(1.29)\end{array}$ \\
\hline (Income-rent)/month & $\begin{array}{r}0.056 \\
(3.94)\end{array}$ & $\begin{array}{c}0.156^{\mathrm{a}} \\
(0.28)\end{array}$ & $\begin{array}{c}0.819^{\mathrm{a}} \\
(0.60)\end{array}$ \\
\hline (Income-rent) $)^{2} /$ month & & & $\begin{array}{c}-1.050^{\mathrm{a}} \\
(2.05)\end{array}$ \\
\hline \multicolumn{4}{|l|}{ Log income times: } \\
\hline Single detached & & & $\begin{array}{c}0.483 \\
(1.60)\end{array}$ \\
\hline Duplex & & & $\begin{array}{r}0.459 \\
(1.88)\end{array}$ \\
\hline Age of structure & & & $\begin{array}{c}-0.011 \\
(2.07)\end{array}$ \\
\hline Age of structure ${ }^{2}$ & & & $\begin{array}{c}0.230 \\
(1.93)\end{array}$ \\
\hline Condition & & & $\begin{array}{c}-0.952 \\
(4.03)\end{array}$ \\
\hline Condition $^{2}$ & & & $\begin{array}{r}0.337 \\
(0.42)\end{array}$ \\
\hline Baths & & & $\begin{array}{r}0.453 \\
(1.71)\end{array}$ \\
\hline Baths $^{2}$ & & & $\begin{array}{c}-1.360 \\
(1.46)\end{array}$ \\
\hline Bedrooms/person & & & $\begin{array}{c}0.582 \\
(2.44)\end{array}$ \\
\hline (Bedrooms/person) $^{2}$ & & & $\begin{array}{r}-3.340 \\
(8.92)\end{array}$ \\
\hline Log likelihood & -914.12 & -936.09 & -821.27 \\
\hline $\begin{array}{l}\text { Likelihood ratio } \\
\text { statistic }\left(\chi^{2}\right)\end{array}$ & 48.36 & 4.43 & 234.06 \\
\hline
\end{tabular}

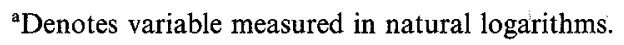


dwellings of increased size, but that preferences for larger dwellings increase with income at a decreasing rate.

Table 4 presents estimates of the choice of neighborhood conditional upon town, and tests for the independence of irrelevant alternatives across dwcllings. The model includes variables mcasuring the proportion of owncr occupants in the census tract (neighborhood) and the median rent of dwellings. Presumably, neighborhoods with a larger fraction of owner occupants arc more desirable, as arc ncighborhoods where avcrage rents arc higher. The model also includes two measures of accessibility - the commuting time by auto and public transit from the home census tract to the tract containing the workplace for the head of the houschold. The model also contains variables measuring the fraction of black households in the neighborhood, multiplied by a dummy variable indicating the race of the houschold.

Table 4

Coefficient estimates for neighborhood choice, given town ( $t$-ratios in parentheses).

\begin{tabular}{|c|c|c|c|}
\hline & Model 1 & Model 2 & Model \\
\hline \multicolumn{4}{|l|}{ Neighborhood characteristics } \\
\hline Proportion homeowners & $\begin{array}{l}0.0443 \\
(0.13)\end{array}$ & $\begin{array}{c}-0.1261 \\
(0.38)\end{array}$ & $\begin{array}{c}-0.0314 \\
(0.09)\end{array}$ \\
\hline Median rent (1970 dollars) & $\begin{array}{l}0.0001 \\
(0.05)\end{array}$ & $\begin{array}{c}-0.0002 \\
(0.09)\end{array}$ & $\begin{array}{l}0.0011 \\
(0.59)\end{array}$ \\
\hline $\begin{array}{l}\text { Auto travel time } \\
\text { (monthly commute in hours) }\end{array}$ & $\begin{array}{l}-0.0405 \\
(4.39)\end{array}$ & $\begin{array}{c}-0.0371 \\
(4.09)\end{array}$ & $\begin{array}{l}-0.0393 \\
(4.28)\end{array}$ \\
\hline $\begin{array}{l}\text { Public transit travel time } \\
\text { (monthly commute in hours) }\end{array}$ & $\begin{array}{l}-0.0008 \\
(2.17)\end{array}$ & $\begin{array}{l}-0.0117 \\
(3.05)\end{array}$ & $\begin{array}{l}-0.0102 \\
(2.60)\end{array}$ \\
\hline $\begin{array}{l}\text { Proportion Black: } \\
\text { White households }\end{array}$ & $\begin{array}{l}-0.0169 \\
(2.15)\end{array}$ & $\begin{array}{l}-0.7183 \\
(2.61)\end{array}$ & $\begin{array}{l}-0.6512 \\
(2.35)\end{array}$ \\
\hline Black households & $\begin{array}{l}1.1248 \\
(2.08)\end{array}$ & $\begin{array}{l}0.9431 \\
(1.79)\end{array}$ & $\begin{array}{l}1.1426 \\
(2.11)\end{array}$ \\
\hline \multicolumn{4}{|l|}{ Inclusive value } \\
\hline $\log$ (dwelling units), $\log N_{n}$ & $\begin{array}{l}0.0150 \\
(0.18)\end{array}$ & $\begin{array}{c}-0.0024 \\
(0.03)\end{array}$ & $\begin{array}{c}-0.0008 \\
(0.01)\end{array}$ \\
\hline Mean, $\bar{X}_{n}$ & $\begin{array}{l}0.2433 \\
(4.53)\end{array}$ & $\begin{array}{l}0.5303 \\
(2.58)\end{array}$ & $\begin{array}{c}-0.0004 \\
(0.71)\end{array}$ \\
\hline Variance, $W_{n}$ & $\begin{array}{l}0.6950 \\
(1.13)\end{array}$ & $\begin{array}{c}-4.9100 \\
(0.82)\end{array}$ & $\begin{array}{l}-0.0002 \\
(3.47)\end{array}$ \\
\hline Log likelihood & -320.21 & -327.82 & -322.18 \\
\hline $\begin{array}{l}\text { Likelihood ratio } \\
\text { statistic }\left(\chi^{2}\right)\end{array}$ & 163.64 & 148.42 & 159.70 \\
\hline
\end{tabular}


Table $4^{\prime}$

Estimates of degree of independence of irrelevant allernatives for choice of dwelling.

$$
\left(1-\sigma_{n}\right) I_{n}=R \bar{X}_{n}+\left(1-\sigma_{n_{1}}\right) \log N_{n}+\frac{1}{2\left(1-\sigma_{n_{2}}\right)} W_{n} .
$$

Point estimate 95 percent confidence intervals

Model 1

$\begin{array}{lllll}R & 0.2433 & 0.1380 & \text { to } & 0.3486 \\ \sigma_{n_{1}} & 0.9850 & 0.8217 & \text { to } & 1.1483 \\ \sigma_{n_{2}} & 0.2810 & 0.0200 & \text { to } & 1.980\end{array}$

Model 2

$\begin{array}{lllll}R & 0.5303 & 0.1275 & \text { to } 0.9331 \\ \sigma_{n_{1}} & 1.0024 & 0.8466 & \text { to } 1.1592 \\ \sigma_{n_{2}} & 1.1018 & 0.9293 & \text { to } 1.0296\end{array}$

Model 3

\begin{tabular}{lllll}
$R$ & -0.0004 & -0.0015 & to & 0.0007 \\
$\sigma_{n_{1}}$ & 1.0008 & 0.8432 & to & 1.1576 \\
$\sigma_{n_{2}}$ & $-0.2499 \times 10^{4}$ & $-0.4999 \times 10^{4}$ to & $0.1666 \times 10^{4}$ \\
\hline
\end{tabular}

The three models differ in the computation of the inclusive value, included as the three variables in eq. (10). Models 1, 2 and 3 differ in relying upon the coefficients from columns (1), (2) and (3) respectively in table 3 to compute the variables $\bar{X}_{n}$ and $W_{n}$ representing the mean and variance of the inclusive values.

Regardless of the specification of $\bar{X}_{n}$ and $W_{n}$, the coefficients of the other variables are quite stable. There is little evidence that the fraction of homeowners or the median rent makes a neighborhood more attractive to these lower-middle income renter households. Both measures of accessibility are highly significant, indicating that the probability of choosing a neighborhood, within town, is highly sensitive to the accessibility of the neighborhood to the worksite of the household. Other things being equal, a given reduction in auto commuting time has three or four times the importance in affecting choice as an equivalent reduction in commuting time by public transit.

The racial composition of the local area is clearly important in affecting household choice of neighborhood. Ceteris paribus, black households are considerably more likely to choose dwellings in neighborhoods containing a larger fraction of blacks, and white households are less likely. On the basis of 
the model alone, we are unable to distinguish whether this results from self segregation by race or from the operation of a discriminatory housing market.

Table 4 also reports the coefficients of the three variables related to the inclusive value for dwelling units: the logarithm of the number of dwellings within a given census tract; the mean value of $X_{n}$ estimated for that tract; and an estimate of its variance. The implications of these coefficients are indicated in Table $4^{\prime}$. According to the thcory, the cocfficient $R$ of the mean value of $X_{n}$ should be 1 , the coefficient of the number of dwellings should be $1-\sigma_{n}$, and the coefficient of the variance term should be $1 /\left(2\left(1-\sigma_{n}\right)\right)$. Each model thus provides two estimates of $\sigma_{n}$. To be consistent with utility maximization, the value of $\sigma_{n}$ should lie between 0 and 1 . As the table indicates, the point estimates of $\sigma_{n}$ derived from the $\log N_{n}$ term are very close to 1 .

Table 5

Estimates of town choice ( $t$-ratios in parentheses).

\begin{tabular}{|c|c|c|c|c|c|c|}
\hline & \multicolumn{2}{|l|}{ Model 1} & \multicolumn{2}{|l|}{ Model 2} & \multicolumn{2}{|l|}{ Model 3} \\
\hline & A & B & A & B & A & B \\
\hline \multicolumn{7}{|l|}{ Town characteristics } \\
\hline $\begin{array}{l}\text { School expenditures } \\
\text { per } \operatorname{ADM}\left(\times 10^{4}\right)\end{array}$ & $\begin{array}{c}-0.0365 \\
(3.00)\end{array}$ & $\begin{array}{l}-0.0365 \\
(2.85)\end{array}$ & $\begin{array}{c}-0.0428 \\
(3.56)\end{array}$ & $\begin{array}{c}-0.4316 \\
(3.37)\end{array}$ & $\begin{array}{c}-0.0444 \\
(3.86)\end{array}$ & $\begin{array}{l}-0.04263 \\
(3.42)\end{array}$ \\
\hline $\begin{array}{l}\text { Public expenditures } \\
\text { per household }\left(\times 10^{4}\right)\end{array}$ & $\begin{array}{c}-0.0013 \\
(3.28)\end{array}$ & $\begin{array}{c}-0.0013 \\
(3.28)\end{array}$ & $\begin{array}{c}-0.0013 \\
(3.71)\end{array}$ & $\begin{array}{c}-0.0013 \\
(3.51)\end{array}$ & $\begin{array}{c}-0.0013 \\
(4.06)\end{array}$ & $\begin{array}{c}-0.0013 \\
(3.55)\end{array}$ \\
\hline $\begin{array}{l}\text { Proportion black in schools: } \\
\text { White households } \\
\left(\times 10^{4}\right)\end{array}$ & $\begin{array}{l}0.1335 \\
(6.02)\end{array}$ & $\begin{array}{l}0.1328 \\
(5.90)\end{array}$ & $\begin{array}{l}0.1425 \\
(6.64)\end{array}$ & $\begin{array}{l}0.1359 \\
(5.87)\end{array}$ & $\begin{array}{l}0.1356 \\
(6.52)\end{array}$ & $\begin{array}{l}0.1257 \\
(5.70)\end{array}$ \\
\hline $\begin{array}{l}\text { Black households } \\
\left(\times 10^{4}\right)\end{array}$ & $\begin{array}{l}0.1402 \\
(1.91)\end{array}$ & $\begin{array}{l}0.1380 \\
(1.85)\end{array}$ & $\begin{array}{l}0.1415 \\
(1.99)\end{array}$ & $\begin{array}{l}0.1354 \\
(2.02)\end{array}$ & $\begin{array}{l}0.1465 \\
(2.19)\end{array}$ & $\begin{array}{l}0.1471 \\
(2.20)\end{array}$ \\
\hline Auto transit time & & $\begin{array}{c}-0.0085 \\
(0.10)\end{array}$ & & $\begin{array}{c}-0.1247 \\
(1.82)\end{array}$ & & $\begin{array}{c}-0.2202 \\
(3.13)\end{array}$ \\
\hline Transit travel time & & $\begin{array}{c}-0.0033 \\
(0.17)\end{array}$ & & $\begin{array}{c}-0.0282 \\
(1.20)\end{array}$ & & $\begin{array}{l}-0.0482 \\
(2.80)\end{array}$ \\
\hline \multicolumn{7}{|l|}{ Inclusive value } \\
\hline Log (dwelling units), $\log N_{t}$ & $\begin{array}{l}0.6683 \\
(1.68)\end{array}$ & $\begin{array}{l}0.6644 \\
(1.66)\end{array}$ & $\begin{array}{l}0.6100 \\
(1.66)\end{array}$ & $\begin{array}{l}0.6749 \\
(1.75)\end{array}$ & $\begin{array}{l}0.5219 \\
(1.46)\end{array}$ & $\begin{array}{l}0.6767 \\
(1.78)\end{array}$ \\
\hline Mean, $\bar{X}_{t}$ & $\begin{array}{l}0.7939 \\
(6.06)\end{array}$ & $\begin{array}{l}0.7399 \\
(1.50)\end{array}$ & $\begin{array}{l}0.7987 \\
(6.51)\end{array}$ & $\begin{array}{l}0.0457 \\
(0.10)\end{array}$ & $\begin{array}{l}0.7326 \\
(6.43)\end{array}$ & $\begin{array}{c}-0.4874 \\
(1.27)\end{array}$ \\
\hline Variance, $W_{t}$ & $\begin{array}{l}2.0215 \\
(3.28)\end{array}$ & $\begin{array}{l}2.0162 \\
(3.25)\end{array}$ & $\begin{array}{l}1.2966 \\
(3.26)\end{array}$ & $\begin{array}{l}1.3458 \\
(3.10)\end{array}$ & $\begin{array}{l}0.9686 \\
(2.32)\end{array}$ & $\begin{array}{l}1.1321 \\
(2.59)\end{array}$ \\
\hline Log likelihood & -43.45 & -43.44 & -48.99 & -46.56 & -53.75 & -47.26 \\
\hline $\begin{array}{l}\text { Likelihood ratio } \\
\text { statistic }\left(\chi^{2}\right)\end{array}$ & 722.69 & 722.72 & 711.61 & 716.47 & 702.10 & 715.00 \\
\hline
\end{tabular}


Table $5^{\prime}$

Estimates of degree of independence of irrelevant alternatives for choice of neighborhood.

$$
\left(1-\sigma_{t}\right) I_{t}=R \bar{X}_{t}+\left(1-\sigma_{t_{1}}\right) \log N_{t}+\frac{1}{2\left(1-\sigma_{t_{2}}\right)} W_{t}
$$

\begin{tabular}{lcc}
\hline & Point estimate & 95 percent confidence intervals \\
\hline Model 1A & & \\
$R$ & 0.7939 & 0.5371 to 1.0507 \\
$\sigma_{t_{1}}$ & 0.3317 & -0.4480 to 1.1113 \\
$\sigma_{t_{2}}$ & 0.7729 & 0.3853 to 0.8453 \\
Model $1 B$ & & \\
$R$ & 0.7399 & -1.2797 to 2.7595 \\
$\sigma_{t_{1}}$ & 0.3356 & -0.4489 to 1.1201 \\
$\sigma_{t_{2}}$ & 0.7520 & 0.3752 to 0.8453 \\
Model $2 A$ & & \\
$R$ & & \\
$\sigma_{t_{1}}$ & 0.7987 & 0.5582 to 1.0292 \\
$\sigma_{t_{2}}$ & 0.2900 & -0.3300 to 1.1100 \\
Model $2 B$ & 0.6144 & 0.0329 to 0.7592 \\
$R$ & & \\
$\sigma_{t_{1}}$ & 0.0457 & -0.8540 to 0.9414 \\
$\sigma_{t_{2}}$ & 0.3251 & -0.4308 to 1.0810 \\
Model $3 A$ & 0.6285 & -1.1057 to 0.7723 \\
$R$ & & \\
$\sigma_{t_{1}}$ & 0.7326 & 0.5093 to 0.9559 \\
$\sigma_{t_{2}}$ & 0.4781 & -0.2225 to 1.1787 \\
Model $3 B$ & 0.4838 & -4.3266 to 0.7202 \\
$R$ & & \\
$\sigma_{t_{1}}$ & -0.4874 & -1.2396 to 0.2648 \\
$\sigma_{t_{2}}$ & 0.3233 & -0.4218 to 1.0681 \\
\hline & 0.5583 & -2.6311 to 0.7486 \\
\hline & &
\end{tabular}

Table 5 presents marginal estimates of town choice for the 584 households. The model includes school expenditures per student, municipal expenditures per household, and measures of the racial composition of the political jurisdiction: the proportion black multiplied by a dummy variable for black households or another dummy variable for white households. Although the magnitudes are quite small, these results suggest that these households choose to live in towns where school expenditures and other public expenditures are lower. In the metropolitan Pittsburgh context, this means ceteris paribus that they are far more likely to choose residences outsidc the central city. In contrast to the results reported for neighborhoods, there are essentially no differences in the racial composition of towns selected by black 
and white households. The coefficients of the racial composition variable are virtually identical for black and white households.

When the transit time variables are added to the models, they have the anticipated sign. Presumably, however, the principal role of accessibility variation has bcen accountcd for in the choice of neighborhood.

Table $5^{\prime}$ presents the implications of the coefficients of the $\bar{X}_{t}, W_{t}$ and $\log N_{t}$ variables.

For model 1 , the estimate of $R$ is insignificantly different from one, the value implied by the theory. The confidence intervals for $\sigma_{t}$ computed from the coefficient on $\log N_{t}$ include the entire $[0,1]$ interval with 95 percent confidence, whilc the confidence interval computed from the coefficient on $W_{t}$ is somewhat narrower and excludes the values of 0 and 1 . The estimates computed from models 2 and 3 are far less precise.

\section{Implications of the more general model of consumer choice}

On the criterion of consistency with economic theory, model 1 appears superior to the other specifications. Stochastic utility maximization requires that the estimates of $\sigma_{n}$ and $\sigma_{t}$ lie between 0 and 1 and that the estimate of $\sigma_{t}$ exceed the estimate of $\sigma_{n}$. For model 1 (in contrast to model 2) the coefficients of dwelling attributes are highly significant (see table 3 ). Moreover, in contrast to model 3 , all point estimates of the $\sigma$ 's lie between 0 and 1 (sce table 4). Parsimony further suggests that model $1 \mathrm{~A}$ is preferred, and the requirements for utility maximization, $\sigma_{t} \geqq \sigma_{n}$, indicate that the estimates of $\sigma$ computed from the variance term are to be preferred (i.e., $\sigma_{t}=0.7729, \sigma_{n}=0.2811$, respectively). ${ }^{5}$

The economic implications of the coefficient estimates of model 1A appear plausible, especially when the results of the more general analysis are comparcd to those derived assuming $\sigma_{t}=\sigma_{n}=0$. For examplc, the cocficients reported in table 3 suggest that households are willing to pay $\$ 13.18$ per month $(0.738 / 0.056)$ for an additional bedroom and $\$ 5.34$ for an additional bath. Thesc households appcar to be willing to pay $\$ 6.63$ per month more for a single detached unit and $\$ 4.57$ more for a duplex than for higher density apartment accommodations.

From the cocfficients in tables 3 and 4, it appears that households are willing to bid a substantial premium for a more accessible location. For

\footnotetext{
${ }^{5}$ It would have been possible, of course, to have constrained the coefficients on the $\log N$ and $W$ terms in tables 4 and 5 so that a single maximum likelihood estimate of $\sigma$ was produced (i.e., by constraining the coefficient on $W$ to be one half the reciprocal of the coefficient on $\log N$ ). This would have required substantially altering the iterative maximization algorithm. It would also have been possible, however, to have estimated a single maximum likelihood $\sigma$, conditional upon the inefficient maximization algorithm, by minimizing the quadratic form of the variance covariance matrix of estimated parameters (i.e., by choosing $\sigma$ to minimize $(1-\sigma, 1 /[2(1-\sigma)]) V(1-\sigma$, $1 /[2(1-\sigma)])$, where $V$ is the variance-covariance matrix of the estimated coefficients of $\log N$ and $W$ ). In retrospect, it was clearly a mistake not to have printed out the required covariances.
} 
example, to save one hour of commuting time by car per month, households are willing to pay $\$ 2.29$ per month in higher rent (i.e., 0.0405/ $[0.056(1-0.7729) /(1-0.2811)])$, or about 62 percent of the average pre tax hourly wage. Interestingly, if the implicit value of accessibility is computed using the conventional IIA assumptions (i.e., $\sigma_{n}=\sigma_{t}=0$ ), the estimated value of commuting time is considerably lower, $\$ 0.72$ (i.e., $0.040 / 0.056$ ) or less than 20 percent of the wage.

It is possiblc to compare the predictions of the well specified model with those implied maintaining the assumption that $\sigma_{n}=\sigma_{t}=0$. Given the double nested form of the utility function, the log odds of choosing dwelling $i$ in neighborhood $j$ and town $k$ rclative to dwelling $x$ in neighborhood $y$ and town $z$ may be expressed as

$$
\begin{aligned}
& \log \left[P(i, j, k)^{\prime} P(x, y, z)\right] \\
& =\frac{\left[A_{i}\right] /\left(1-\sigma_{n}\right)+\left[B_{j}+\left(1-\sigma_{n}\right) I_{j}\right] /\left(1-\sigma_{t}\right)+\left[\left(1-\sigma_{t}\right) C_{k}+\left(1-\sigma_{n}\right) I_{k}\right] /\left(1-\sigma_{t}\right)}{\left[A_{x}\right] /\left(1-\sigma_{n}\right)+\left[B_{y}+\left(1-\sigma_{n}\right) I_{y}\right] /\left(1-\sigma_{t}\right)+\left[\left(1-\sigma_{t}\right) C_{z}+\left(1-\sigma_{n}\right) I_{z}\right] /\left(1-\sigma_{t}\right)}
\end{aligned}
$$

where $A_{p}, B_{q}$ and $C_{r}$ are, respectively, the sums of the housing, neighborhood and town variables for dwelling $p$ in the neighborhood $q$ and town $r$ multiplied by their coefficients reported in tables 3,4 , and 5 , and $I_{q}$ and $I_{r}$ are the inclusive values for neighborhood $q$ and town $r$.

Table 6 presents estimates of the odds of choosing between two representative dwellings in each of two neighborhoods in each of two towns. Dwelling 1 is a 10 year old single detached unit in sound condition with one bedroom per person and two baths. Dwelling 2 is a 25 year old duplex unit, deteriorating, with one bath and half a bedroom per person. Dwelling 1 rents for $\$ 10$ more per month than dwelling 2 . The neighborhoods differ in racial composition and accessibility. Neighborhood 1 is more accessible to work ( 6 hours a month by auto and 15 hours by public transit) and has a 20 percentage point larger black population than neighborhood 2. The towns differ in that an additional $\$ 1,000$ per household and $\$ 300$ per student is spent in town 2. The table contains separate estimates for white and black households.

For the properly specified model, within town 1 and neighborhood 1, the choice of house 1 is about three times as likely $(1 \div 0.35)$, and within town 2 and neighborhood 1, the choice of house 1 is about 2.8 times as likely $(0.88 \div 0.31)$ for white and black households. For the model which assumes the independence of irrelevant alternatives the comparisons, each about 1.5 times as likely $(1 \div 0.65,0.88 \div 0.58)$, are very different indeed.

For the model which incorporates the degree of independence of irrelevant alternatives, white households are 4 times as likely to choose neighborhood 1 
Table 6

Comparisons of the odds of choice among dwellings, neighborhoods, and towns computed by assuming the independence of irrelevant alternatives with odds estimated from more general model. ${ }^{a}$

\begin{tabular}{|c|c|c|c|c|}
\hline & \multicolumn{2}{|c|}{$\begin{array}{l}\text { Assuming IIA } \\
\sigma_{n}=\sigma_{t}=0\end{array}$} & \multicolumn{2}{|c|}{$\begin{array}{l}\text { Estimating degree of IIA } \\
\sigma_{n}=0.281, \sigma_{t}=0.773\end{array}$} \\
\hline & House 1 & House 2 & House 1 & House 2 \\
\hline \multicolumn{5}{|l|}{ White households } \\
\hline \multicolumn{5}{|l|}{ Town 1} \\
\hline Neighborhood 1 & 1.00 & 0.65 & 1.00 & 0.35 \\
\hline Neighborhood 2 & 0.69 & 0.45 & 0.23 & 0.08 \\
\hline \multicolumn{5}{|l|}{ Town 2} \\
\hline Ncighborhood 1 & 0.88 & 0.58 & 0.88 & 0.31 \\
\hline Neighborhood 2 & 0.61 & 0.40 & 0.20 & 0.07 \\
\hline \multicolumn{5}{|l|}{ Black households } \\
\hline \multicolumn{5}{|l|}{ Town 1} \\
\hline Neighborhood 1 & 1.00 & 0.65 & 1.00 & 0.35 \\
\hline Neighborhood 2 & 0.50 & 0.33 & 0.06 & 0.02 \\
\hline \multicolumn{5}{|l|}{ Town 2} \\
\hline Neighborhood 1 & 0.88 & 0.58 & 0.88 & 0.31 \\
\hline Neighborhood 1 & 0.44 & 0.29 & 10.05 & 0.02 \\
\hline
\end{tabular}

${ }^{a}$ Odds are expressed relative to the probability of choosing house 1 in neighborhood 1 in town 1 . Computations are made assuming the same number of dwellings in each neighborhood and the same number of neighborhoods in each town. See text for definitions of house 1,2, neighborhood 1, 2 and town 1,2 .

in town $1(1 \div 0.23)$ and 4.4 times as likely in town $2(0.88 \div 0.20)$. For the less general model, the comparisons, each about 1.4 , are again very different. Other comparisons also reveal substantial differences in the odds of choice estimated using the two models.

Finally, fig. 2 provides an illustration of the contrasting implications of the two models. For white households, panels a and b graph the odds of choosing between two houses as a function of their differences in accessibility (as measured by variations in monthly commuting times). Panel a presents the odds of choosing between two dwellings (of the 'house 1' variety) which differ only in their accessibility to the worksite of the household. The relationship is graphed separately for the model which assumes the IIA property and for the more general formulation. As the figure indicates, with no difference in accessibility, the consumer is indifferent between the dwellings (and from both models the odds are computed to be 1 to 1 ). The figure indi- 

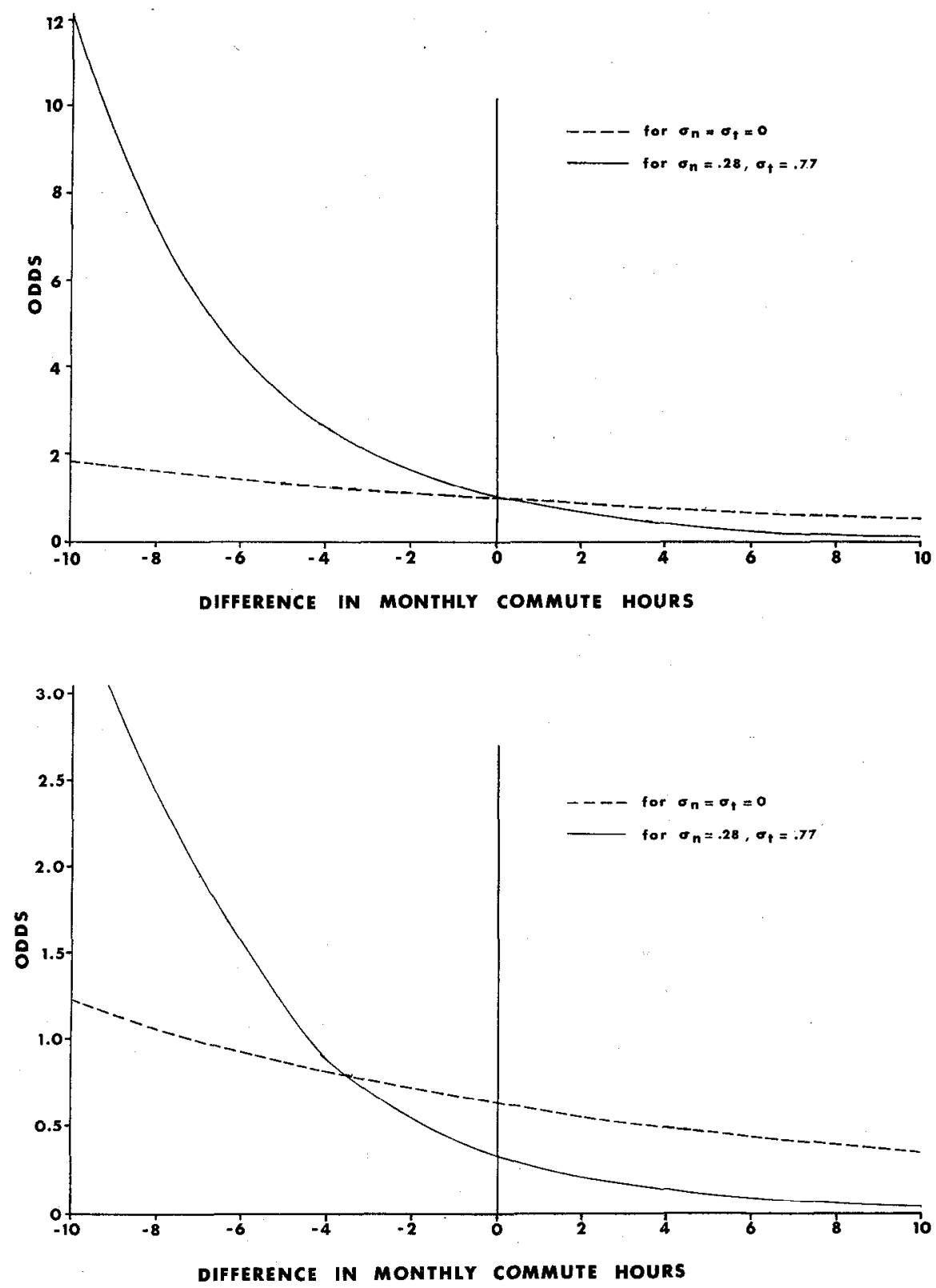

Fig. 2. Odds of housing choice at various community differences. 
cates that if the IIA property is assumed, an otherwise identical dwelling that saves four hours a month in auto commuting time due to its superior location is preferred by about 1.5 to 1 . According to the more general model, however, the more accessible dwelling is preferred by about 3 to 1. Similarly, the restricted model indicates that an eight hour per month saving in commuting time increases the odds of choosing the more accessible, but otherwise identical, dwelling to about 1.75 to 1 . In contrast, the more general model suggests that the true odds are substantially higher - about 9 to 1 .

Panel $b$ presents a similar comparison of the odds of choice between two different dwellings (a 'house 2' type relative to a 'house 1') in identical neighborhood and towns as accessibility to the worksite varies. At the same commuting time, the restricted model that assumes the IIA property estimates the choice odds to be 0.65 to 1 . As the 'type 2' house becomes more accessible, it is more likely to be chosen; at a six hour monthly savings in commuting time the odds are estimated to be about 1 to 1 . The more general model suggests that the choice odds are much more sensitive to variations in accessibility. At the same accessibility, it is estimated that the odds of choosing a 'type 2' house relative to a 'type 1' house are about 0.35 to 1 , but at a saving of six hours a month in commuting time the odds are increased to about 2 to 1 .

The results indicate quite clearly that, at least for this particular body of data, the implications of the more general model make a substantial difference in the economic interpretation of consumer choice and in the importance of workplace accessibility to household choice in the market for owner-occupied housing.

\section{References}

Case, Karl L., 1981, A new approach to modeling the effects of demographic changc on the housing market, Working paper no. 42 (Department of Economics, Wellesley College, Wellesley, MA).

Domencich, Thomas A. and Daniel McFadden, 1975, Urban travel demand: A behavioral analysis (North-IIolland, Amsterdam).

Ellickson, Bryan, 1977, Economic analysis of urban housing markets: A new approach, R-2024NSF (Rand Corporation, Santa Monica, CA).

Ellickson, Bryan, 1981, An alternative test of the hedonic theory of housing markets, Journal of Urban Economics 9, 56-79.

Kain, John F. and William C. Apgar, Jr., 1977, The modeling of the neighborhood change, Discussion paper D77-22 (Department of City and Regional Planning, Harvard University, Cambridge, MA).

Lerman, Stephen R., 1977, Location, housing, automobilc ownership, and the mode to work: A joint choice model, Transportation Research Board Record 610, 6-11.

Lerman, Stephen R., 1979, Neighborhood choice and transportation services, in: David Segal, ed., The economics of neighborhood (Academic Press, New York) 83-118.

McFadden, Daniel, 1974, Conditional logit analysis of qualitative choice behavior, in: Paul Zarembka, ed., Frontiers in Econometrics (Academic Press, New York) 105-140.

McFadden, Daniel, 1978, Modelling the choice of residential location, in: Anders Karlqvist et al. eds., Spatial interaction theory and planning models (North-Holland, Amsterdam) 75-96. 
Quigley, John M., 1972, Residential location with multiple workplaces and a heterogeneous housing stock, Discussion paper no. 80 (Program on Regional and Urban Fconomics, Harvard University, Cambridge, MA).

Quigley, John M., 1976, Housing demand in the short run: An analysis of polytomous choice, Explorations in Economic Research 3, 76-102.

Quigley, John M., 1983, Estimates of a more general model of housing choice, in: Ronald $\mathrm{F}$. Grieson ed., The urban economy and housing (Lexington Books, Lexington, MA) 125-141.

Quigley, John M., Gail M. Trask and James H. Trask, 1977, Income and product accounts for the local public sector, Working paper no. 795 (Institution for Social and Policy Studies, Yale University, New Haven, CT).

Williams, Roberton C. Jr., 1979, A logit model of demand for neighborhood, in: David Segal, ed., The economics of neighborhood (Academic Press, New York) 17-42. 